\title{
Stress Analysis and Design of Main Reducer Housing Using Finite Element Method
}

\author{
S. Wang \\ School of Mechanical Science and Engineering, Jilin University, Chang Chun, 130022, China
}

\begin{abstract}
The main reducer housing takes over the shaft loads from gear engagement and transmits to other components, such as differential, semiaxle and driving wheels, so the main reducer housing with enough strength and stiffness is very important. Some factors preventing it from failure need to be taken into consideration when design it. To design a main reducer housing with better performance, in this paper, FEA (Finite Element Analysis) is used to analysis the main reducer housing and to find out some big stress regions. Then, some modifications are proposed to eliminate those big stress regions and obtain a reliable main reducer housing. During the analysis process, an annulus model is built and the reaction forces between the differential bearing seats and axle housing are calculated to determine whether they contact with each other. Finally, some design methods and improvements of the original design main reducer housing are proposed. And numerical comparison results of the stress distribution of the original and improved main reducer housing validate the effectiveness of the proposed methods and modifications in this paper. Those stress analysis and modifications in this paper are time-saving and money-saving before mass production.

Keywords: main reducer housing, tress analysis, FEA
\end{abstract}

\section{Introduction}

The main reducer housing, a basic structural component of axle assembly, is able to reduce the rotation speed and enhance the torque significantly[1]. It takes over the shaft loads from gear engagements and delivers those driving forces to other components, such as differential gears, semiaxis and driving wheels. The main reducer housing with enough strength and stiffness ensure more accurate gear engagements and better performance of transmission system, avoiding a disaster during work caused by failure. Therefore, making sure the main reducer housing has enough strength and stiffness is very important. The stress analysis is aim to find out some potential problem regions of the main reducer housing and make some improvements of its structure. Besides, the analysis results can be used to instruct the design of the main reducer housing, which may time-saving and money-saving before mass production. The main reducer housing in the axle assembly of a heavy commercial vehicle is shown in Figure 1.

Some studies about strength of the main reducer housing can be found, such as stress distribution of the main reducers housing using FEA [2 3 4]. The lightweight design about the main reducer housing is also studied [5]. But less study about the boundary conditions between the main reduce housing and axle can be found, which have significant influences on FEA.

To get more accurate stress distribution of the main reducer, FEA is carried out. To deal with the boundary conditions, an annulus model is built and reaction forces are calculated. Finally, some noticeable methods to design the main reducer housing are proposed according to the stress distribution. This paper is organized as follows. A full scale finite element model of the main reducer housing is built in section 2.1. Loads and boundary conditions of the main reducer housing are discussed and determined in section 2.2. In section 2.3, potential problem regions of the main reducer housing are found out. In section 3 , some design enhancement solutions and modifications are put forward and applied to the main reducer housing. Comparisons between the main reducer housing stress distribution before and after improvement are also shown in this section. Finally, some conclusions about redesign of the main reducer housing are given out and verified in the end of this paper.

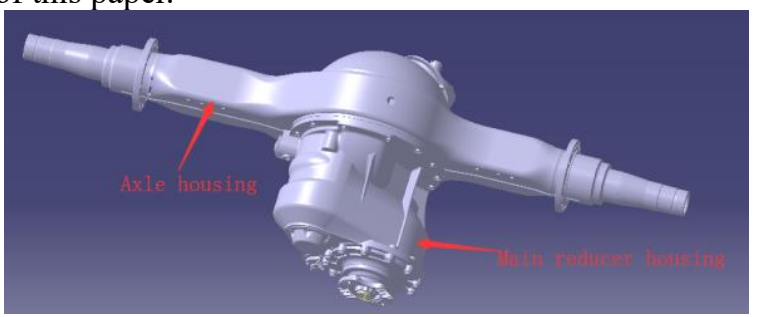

Figure 1. Typical axle assembly in heavy commercial vehicle.

\section{Finite element analysis}

\subsection{FEA model}


FEA is carried out with a full scale model of the main reducer housing. The FEA model is built with high-quality meshes in Figure 2 consisting of 437860 elements and 732016 notes. During the modeling process, meshes of the main reducer housing should be just refined in local regions with consideration of less calculating time, especially in the critical regions, which is called local refinement of meshes.

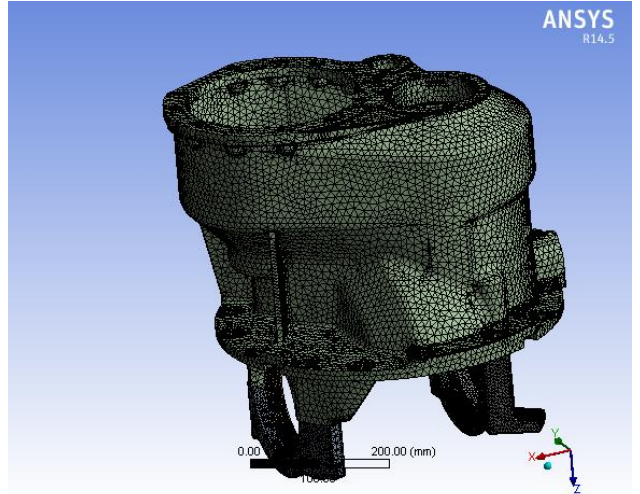

Figure 2. Discretized model of main reducer housing.

\subsection{Loads and Boundary Conditions}

The main reducer housing mounted on the axle housing through flange and bolts and it constrained in all the translational and rotational DOF's. Some small intervals between the axle housing and differential bearing seats exist. They may disappear when the main reducer housing experiences some deformations, causing the axle housing contacts with the differential bearing seats in nonlinear and preventing more deformation of the differential bearing seats and the main reducer housing. Figure 3 shows the details of those seven bearing loads and boundary conditions of the main reducer housing.

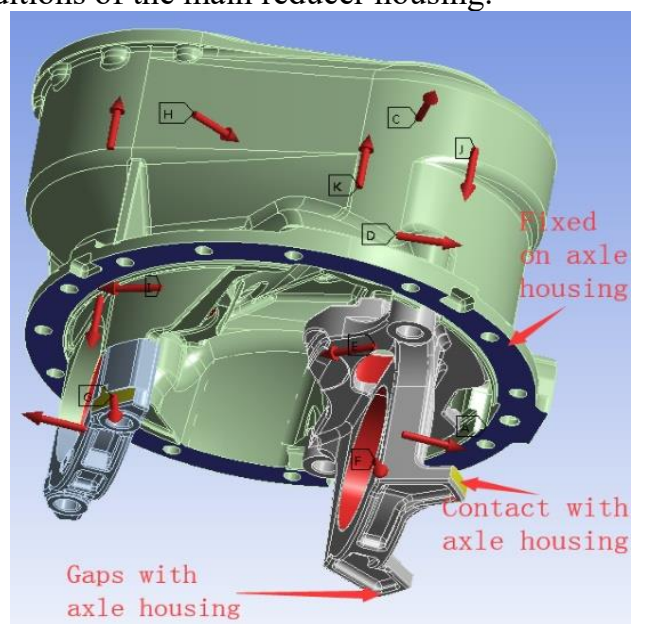

Figure 3. Boundary conditions and bearing loads of main reducer housing.

Two methods dealing with the boundary conditions of the axle housing and the differential bearing seats are pointed out in this section. The first one that an annulus model is built around differential bearing seats to simulate the axle housing and set intervals between them in Figure 4. The second one is that the reaction forces and deformations of those two differential bearing seats are calculated, which indicate whether intervals between them are equal to zero, which means the axle housing contacts with the differential bearing seats. These directions and magnitudes of reaction forces are shown in Figure 5.

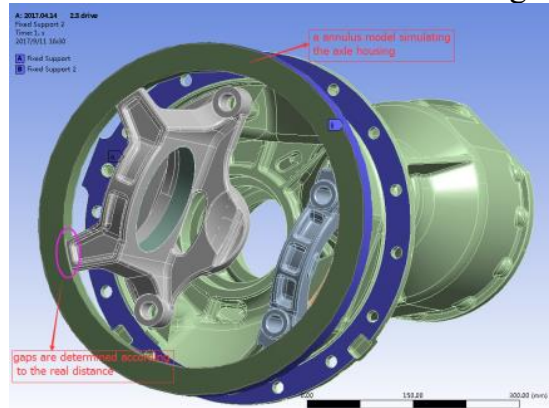

Figure 4. Annulus model around differential.

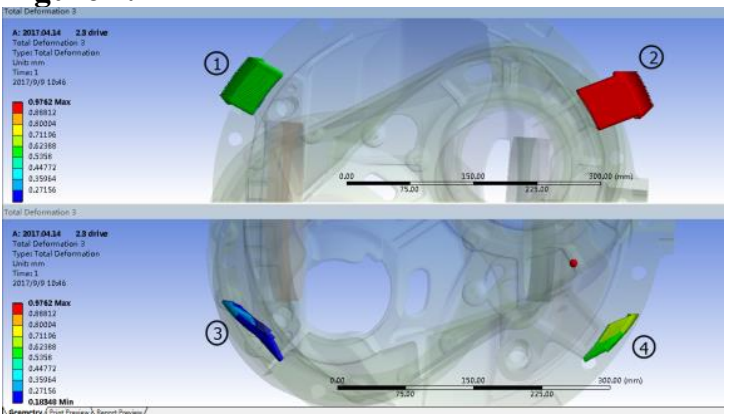

Figure 5. Directions of reaction forces.

From Figure 5, the directions of reaction forces numbered 1 and 2 are perpendicular to differential bearing seats which indicate the differential bearing seats numbered 1 and 2 contact with axle housing. The directions of reaction forces numbered 3 and 4 indicate intervals exist between them. According to the analysis of reaction forces, the differential bearing seats numbered 1 and 2 should be constrained in all translational and rotational DOF's, while those numbered 3 and 4 should be free in all directions during FEA.

\subsection{Results of FEA}

The material of the main reducer housing is ductile iron, yield strength is $310 \mathrm{MPa}$, modulus of elasticity is $1.69 \times 10^{5}$ and poisson ratio is 0.257 . According to the stress distribution, some big stress regions and low stress regions are pointed out. Figure 6(a) and Figure 6(b) show the stress concentration regions of the main reducer housing at the root of the differential bearing and guide bearing seats, while Figure 6(c) shows the low stress regions at the exterior stiffeners. 


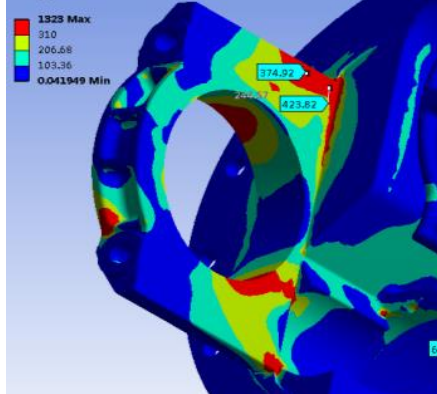

(a)

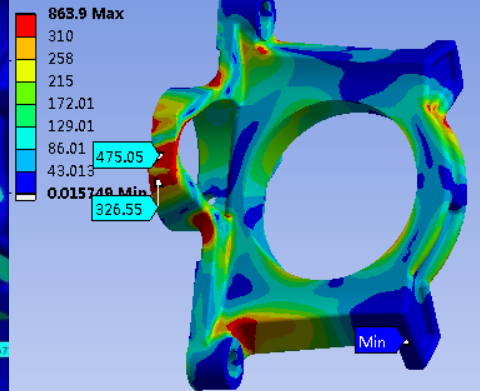

(b)

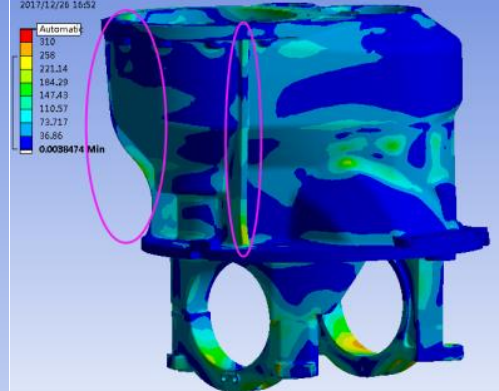

(c)

Figure 6. (a) Stress concentration at the root of differential bearing seat. (b) Stress concentration at the guide bearing seat. (c) Low stress region of exterior stiffeners.

\section{Improved design of main reducer housing}

\subsection{Improved design of stress concentration regions}

To get a better stress distribution, the stress concentration regions need to be eliminated. Increasing the thickness of structure with big stress regions is a common way but not a prefer solution, which may cause poor efficiency with mass increase during work. Given this, the roots of differential bearing seats are expanded as shown in Figure 7(a) compared with Figure6(a), and the guide bearing seat is thickened in Figure 7(b) compared with Figure6(b). Besides, the stiffeners are shortened for mass reduction in Figure 7(c) without big stress compared with Figure6(c). With these modifications, significant improvements appear in stress distribution of the main reducer housing. In order to further verify the effectiveness of these modifications, FEA is carried out again and the analysis results are shown below.

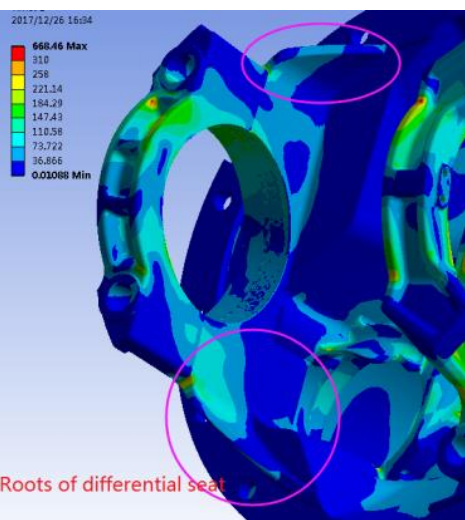

(a)

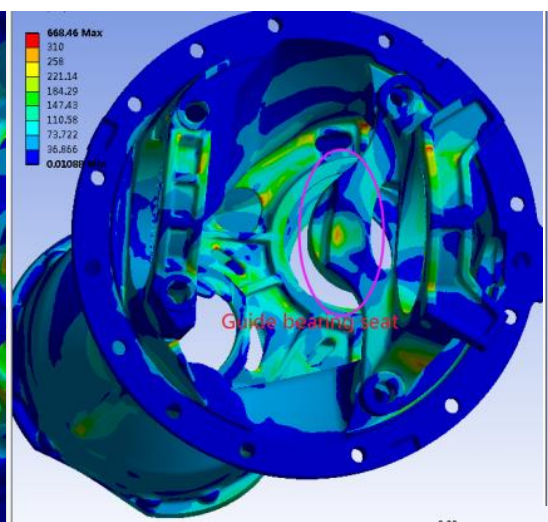

(b)

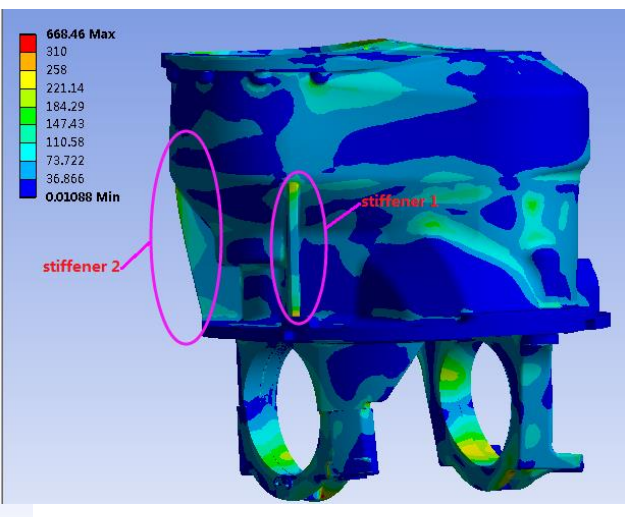

(c)

Figure 7. (a) Improvement of the differential bearing seats. (b) Improvement of the guide bearing seats. (c) Improvement of exterior stiffeners.

\subsection{Comparisons of the original and improved main reducer housing}

Combined with the improvement methods and FEA, better stress distribution of the main reducer housing are obtained. Figure 8 and Table 1 show stress distribution of local part of the main reducer housing and stress comparisons of the original and improved main reducer housing respectively. From those Figures, the strength of the main reducer housing really improve a lot than before, which can ensure safety in practice. The stress distribution of those circled areas in Figure 8 verify the validity of those improvement methods proposed in this paper.

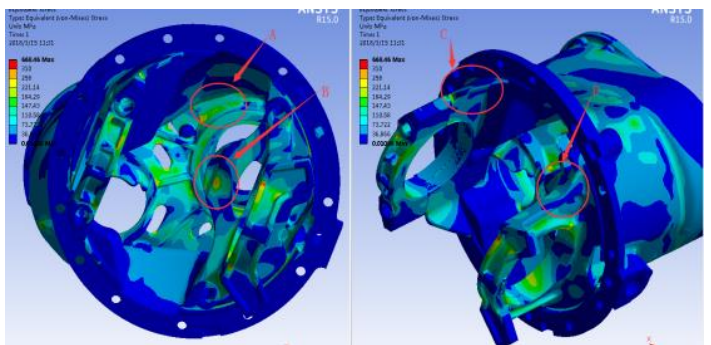

Figure 8. Modified points of main reducer housing. 
Table 1. Stress comparisons between original and improved main reducer housing.

\begin{tabular}{ccccc}
\hline & $\mathrm{A}(\mathrm{MPa})$ & $\mathrm{B}(\mathrm{MPa})$ & $\mathrm{C}(\mathrm{MPa})$ & $\mathrm{D}(\mathrm{MPa})$ \\
\hline Original & 380 & 440 & 420 & 360 \\
\hline Improved & 170 & 110 & 50 & 150 \\
\hline $\begin{array}{c}\text { Improvement } \\
\text { percentage }\end{array}$ & $55 \%$ & $75 \%$ & $88 \%$ & $58 \%$ \\
\hline
\end{tabular}

\section{Conclusion}

In order to find out big stress regions and to ensure enough strength of the main reducer housing during work, FEA method is carried out in this paper. During the analysis process, Local refinement of meshes are pointed out. Besides, an annulus model and reaction forces dealing with boundary conditions are also used to ensure more precise stress analysis. According to these analysis results of the main reducer housing, some potential problem regions are found out which is accordance with the practice. And some improvement methods aimed at those big stress regions are given out. Then, better stress distributions of improved main reducer housing are obtained. Finally, the stress comparisons between original and improved main reducer housing are given out and verify the effectiveness of those improvement methods proposed in this paper, and the improvement rates indicate low stress with better structural design.

\section{References}

[1] Hu F, Chen L Q, Qi B, 2012 Finite element analysis and optimum design of time-sharing 4WD vehicle main reducer. J. Applied Mechanics \& Materials vol 246-247, ed F Y Cheng and Y Ma pp 692-696.

[2] Chen Y D, 2009 Finite element analysis of the main reducer housing of driving axle. J. Manufacturing Informatization. Vol 37. P 10.

[3] Zhou C, 2016 Finite element analysis on the support stiffness of final drive in vehicle drive axle. $J$.Automotive Engineering. Vol 38. No.8.

[4] Q. Q. Zhao. 2014 Finite element analysis of the main reducer housing of four wheel drive car. J. Journal of Chifeng University (Natural Science Edition). Vol (30).No.4.

[5] Yang C, Qin F, Huang D, 2014 The lightweight design for main reducer shell based on topological optimization method. J. Journal of Mechanical Transmission. 